\title{
Review
}

Jeong-Hyun Kang and Hong-Seop Kho*

\section{Blood contamination in salivary diagnostics: current methods and their limitations}

https://doi.org/10.1515/cclm-2018-0739

Received July 14, 2018; accepted October 31, 2018; previously published online December 4, 2018

\begin{abstract}
The use of saliva samples in clinical studies has increased. However, the diagnostic value of whole saliva is compromised in the presence of blood contamination, owing to the higher levels of analytes in blood compared with those in saliva. The aim of this study was to review the existing methods and their limitations for measuring the levels of blood contamination in saliva. A literature search was performed using Web of Science, SCOPUS, and PubMed databases and 49 articles dealing with salivary diagnostics and measurements of blood contamination were included. Five methods for measuring the degree of blood components in saliva were discussed, including "visual inspection", use of "strip for urinalysis", and detection of plasma proteins such as "hemoglobin", "albumin", and "transferrin". Each method has its limitations, and transferrin has been regarded as the most reliable and valid marker for blood contamination in saliva. However, transferrin in whole saliva may not be solely a product of blood, and its level in whole saliva can be influenced by several factors such as age, gonadal hormones, salivary flow rate, chewing performance, and oral microorganisms. In conclusion, when quantitatively analyzing whole saliva samples, the influence of blood contamination should be considered.
\end{abstract}

Keywords: blood; saliva; salivary diagnostics.

\footnotetext{
*Corresponding author: Hong-Seop Kho, Department of Oral Medicine and Oral Diagnosis, School of Dentistry and Dental Research Institute, Seoul National University, 101 Daehak-ro, Jongno-gu, Seoul, Korea (ROK); and Institute on Aging, Seoul National University, Seoul, Korea (ROK), Phone: +82-2-2072-3989, Fax: +82-2-744-9135, E-mail: hkho@snu.ac.kr. https://orcid.org/0000-0001-9960-9892 Jeong-Hyun Kang: Department of Oral Medicine and Oral Diagnosis, School of Dentistry and Dental Research Institute, Seoul National University, 101 Daehak-ro, Jongno-gu, Seoul, Korea (ROK); and Clinic of Oral Medicine and Orofacial Pain, Institute of Oral Health Science, Ajou University School of Medicine, Suwon, Korea (ROK).

https://orcid.org/0000-0001-7124-8693
}

\section{Introduction}

There is no denying that blood and urine are the most important fluids among the diagnostic fluids, but saliva is rapidly becoming another main diagnostic fluid due to the ease and non-invasiveness of collection procedures [1]. Saliva has been considered as an alternative to blood for detecting viral antibodies and monitoring of the levels of hormones and lipid-soluble drugs. Several commercial kits to detect antibodies of human immunodeficiency virus (HIV), human papillomavirus, and hepatitis C virus using oral fluids have been used at points of care [2]. Similarly, many commercial kits that use saliva for detecting hormones and drugs are also available for research and diagnostic purposes [3-5]. Furthermore, salivary diagnostics has potential applications for Sjögren's syndrome [6], other life-threatening diseases such as cardiovascular diseases, malignancies, Alzheimer's disease, Parkinson's disease, and cystic fibrosis [7-11], and chronic metabolic diseases such as diabetes mellitus and renal disease [12, 13]. The salivary diagnostic spectrum for malignancy encompasses not just oral cancer, but also breast, stomach, pancreas, and lung cancers [14-16]. Furthermore, research advances have resulted in salivary diagnostic tools for head and neck cancer diagnosis (SaliMark $^{\text {TM }}$ OSCC, PeriRx, Broomall, PA, USA; MethDNA-Oral Test $^{\mathrm{TM}}$, Uniquest, Brisbane, Australia; OraMark ${ }^{\mathrm{TM}}$, OncAlert Labs, GA, USA) that could be applied for detecting squamous cell carcinoma at outpatient clinics.

Salivary diagnostics can be divided into qualitative and quantitative categories. For qualitative diagnostics, such as the detection of viral antibodies, the use of saliva as a diagnostic tool has many advantages, and results have shown high levels of sensitivity and specificity $[2,17]$. However, most attempts at salivary diagnostics adopt quantitative strategies, which include several limitations that should be overcome to increase the reliability and accuracy of the diagnostic data. Most of all, no standardized collection and storage procedures of saliva have been established to date [18]. Second, due to wide normal ranges and low concentrations of analytes in saliva compared with those in blood [19], the levels of salivary biomarkers 
could be influenced by blood contamination in saliva. The total protein level in plasma is usually ten to 100 times higher than that in saliva [20,21], and the concentration of immunoglobulin G in serum, in particular, is over 20,000 times higher than that in saliva [22]. The levels of steroid hormones, such as cortisol, testosterone, and dehydroepiandrosterone, are generally up to tens of times in serum than in saliva [5, 20, 23-25]. Whole saliva rather than glandular saliva has been widely used for salivary diagnostics and whole saliva contains constituents of non-salivary gland origin, which include microbes and their products, mucosal exudates, gingival crevicular fluid, and desquamated oral epithelial cells. Therefore, the diagnostic value of whole saliva would be unavoidably compromised in the presence of blood contamination, deriving either from the compromised mucosal integrity or from gingival inflammation. The concentrations of analytes in blood are much higher than those in saliva, therefore, the concentrations of analytes in saliva appear to be abnormally elevated when blood leakage reaches a certain level [26-28]. Thus, the blood contamination in salivary samples inevitably results in errors in analytic results.

Not all analytes are influenced by the presence of blood in saliva. Some proteins in whole saliva are products of salivary glands specifically and are present only in saliva, not in blood. Components such as $\alpha$-amylase, potassium, and phosphate are present in higher concentrations in saliva than in blood [29]. The concentrations of several oxidative stress biomarkers in whole saliva are significantly influenced when more than $1 \%$ blood contamination is present, which could be easily detected by the naked eye [30]. However, considering that the concentrations of many salivary biomarkers could be critically affected by a minimal amount of blood in the samples, it is very important to develop methods for measuring the levels of blood contamination in saliva to improve the diagnostic accuracy of the saliva samples.

The aim of this study was to review the existing methods and their limitations for measuring the levels of blood contamination in saliva and propose the need for developing novel future biomarkers for blood contamination in salivary diagnostics.

\section{Methods}

The present scoping review was conducted via a comprehensive literature search. We did not follow a typical systematic review protocol because the research field is still not sufficiently populated to accommodate systematic reviews or meta-analyses. A literature search was performed using Web of Science, SCOPUS, and PubMed databases from 1980 to 2018, with the following search strategy: ("saliva" AND "blood contamination) OR ("salivary biomarkers" AND "blood") OR ("salivary diagnostics"). Searches of the reference lists from relevant reviews or original articles were also employed to identify further relevant literature. After screening the initial article search, 11 articles were identified as eligible studies that focused on the impacts of blood contamination on the diagnostic power of saliva samples, the methods for measuring levels of blood contamination in saliva, and the plasma components that could interfere with the diagnostic accuracy of the saliva (Table 1). Five methods for measuring the degree of blood components in saliva were extracted, including "visual inspection", use of "strip for urinalysis", and detection of plasma proteins such as "hemoglobin", "albumin", and "transferrin" (Figure 1).

A second literature search was performed using the Web of Science, SCOPUS, and PubMed database from 1980 to February 2018, with the following search strategies: "saliva” AND "blood” AND ("visual” OR "strip" OR "hemoglobin" OR "albumin" OR "transferrin”). The additional searches were modifications of this search, and supplementary articles were sought manually by reviewing the reference lists of the literature from the first and second searches in order to identify further eligible studies that were not detected using key words. Only references with English abstracts and full text were included. One study was written in Japanese but had an English abstract. The following studies were excluded: animal studies, case reports, and abstracts only. After abstract and full-text analysis, 49 articles dealing with salivary diagnostics and measurements of blood contamination were included in this review (Table 1 and Figure 2).

\section{Determining the levels of blood contamination in whole saliva}

\section{Visual inspection}

The degree of blood contamination in saliva samples can be occasionally detected by the naked eye. This simple method can be easily performed by untrained personnel in the field during sample collection. A tint in samples containing $0.1 \%-0.2 \%$ by volume of blood can be detected by visual inspection of whole saliva samples [5, 30]. Several studies have used this method to test hormones or drug levels in saliva [31-34]. However, the levels of blood measurable by transferrin assay or urinalysis strips cannot 
Table 1: Existing methods for measuring the levels of blood contamination in saliva and related references.

\begin{tabular}{|c|c|c|c|}
\hline $\begin{array}{l}\text { Method for measuring the levels } \\
\text { of blood contamination in saliva }\end{array}$ & Advantage and limitation & Reference & $\begin{array}{l}\text { Article adopting the following method } \\
\text { for measuring blood contamination }\end{array}$ \\
\hline \multirow[t]{2}{*}{ Visual inspection } & Easy detecting procedures & & $5,30,31-34$ \\
\hline & $\begin{array}{l}\text { Lower detection sensitivity in } \\
\text { comparison to other methods }\end{array}$ & $26,30,35$ & \\
\hline \multirow[t]{2}{*}{ Application of strip for urinalysis } & $\begin{array}{l}\text { Possibilities of producing false-positive } \\
\text { results }\end{array}$ & 41 & $36-40$ \\
\hline & $\begin{array}{l}\text { Lower detection sensitivity in } \\
\text { comparison to measuring transferrin } \\
\text { levels }\end{array}$ & 26 & \\
\hline \multirow[t]{5}{*}{$\begin{array}{l}\text { Measuring the salivary levels of } \\
\text { hemoglobin }\end{array}$} & $\begin{array}{l}\text { Less detection sensitivity and } \\
\text { reproducibility }\end{array}$ & 45,50 & $42,43-48$ \\
\hline & Influences of obesity & 50 & \\
\hline & $\begin{array}{l}\text { Interference with the measurements of } \\
\text { salivary testosterone }\end{array}$ & 52 & \\
\hline & $\begin{array}{l}\text { Interference with measuring oxidative } \\
\text { stress markers in saliva }\end{array}$ & 30 & \\
\hline & $\begin{array}{l}\text { Less consistency when using strips from } \\
\text { different companies }\end{array}$ & 51 & \\
\hline \multirow{2}{*}{$\begin{array}{l}\text { Measuring the salivary levels of } \\
\text { albumin }\end{array}$} & Influences of tumor cells and obesity & 50,58 & $53-56$ \\
\hline & $\begin{array}{l}\text { Interference of results from proteomic } \\
\text { analysis }\end{array}$ & $59-61$ & \\
\hline \multirow[t]{6}{*}{$\begin{array}{l}\text { Measuring the salivary levels of } \\
\text { transferrin }\end{array}$} & $\begin{array}{l}\text { High detection sensitivity in comparison } \\
\text { to other methods }\end{array}$ & $26,28,63,64$ & $27,65-69$ \\
\hline & $\begin{array}{l}\text { Possibilities of synthesis by salivary } \\
\text { glands and tumor cells }\end{array}$ & $70,71,72$ & \\
\hline & Age-related decrease in saliva & $68,74,75$ & \\
\hline & Influence of female gonadal hormones & 68 & \\
\hline & Influence of chewing ability & 75,77 & \\
\hline & Influence of oral microorganisms & 80,81 & \\
\hline
\end{tabular}

The references in bold indicate the articles from the initial search.

always be detected by the naked eye [26]. One previous study reported that salivary testosterone levels could be altered by a factor of 2 due to blood contamination, even though the sample did not appear to be contaminated with blood on visual inspection [26, 35]. However, in an experiment using a spike-in method, the levels of several oxidative stress markers in saliva were significantly affected only when the level of blood contamination was greater than $1 \%$ [30], though the concentrations of markers normalized to those of total proteins, and not the actual concentrations, were used as the data. Thus, the appropriateness of visual inspection by the naked eye may depend on the salivary components being analyzed, and the application of this method on a routine basis requires careful consideration.

\section{Applying strip for urinalysis in saliva}

The strips for urinalysis (i.e. Hemastix ${ }^{\circledR}$ ), which contain 3,3'5,5'-tetramethylbenzidine have been used to detect blood in saliva [36-40]. This method detects the pseudoperoxidase activity of hemoglobin [28], but endogenous salivary peroxidase is also involved in this reaction and could produce false-positive results for hemoglobin [41]. Furthermore, the detection sensitivity of blood in saliva for this method was lower than that achieved by measuring salivary transferrin [26]. Therefore, the urinalysis strip method is no longer widely used.

\section{Measuring the salivary levels of hemoglobin}

Several previous studies have used hemoglobin as a marker of blood contamination because it is abundantly available in plasma but is non-existent in glandular salivary secretion [42-48]. The hemoglobincyanide method, an internationally accepted reference method, had been adopted to detect hemoglobin in saliva [44]. However, due to the lower hemoglobin concentration in whole saliva compared with those in plasma, the use of this method 


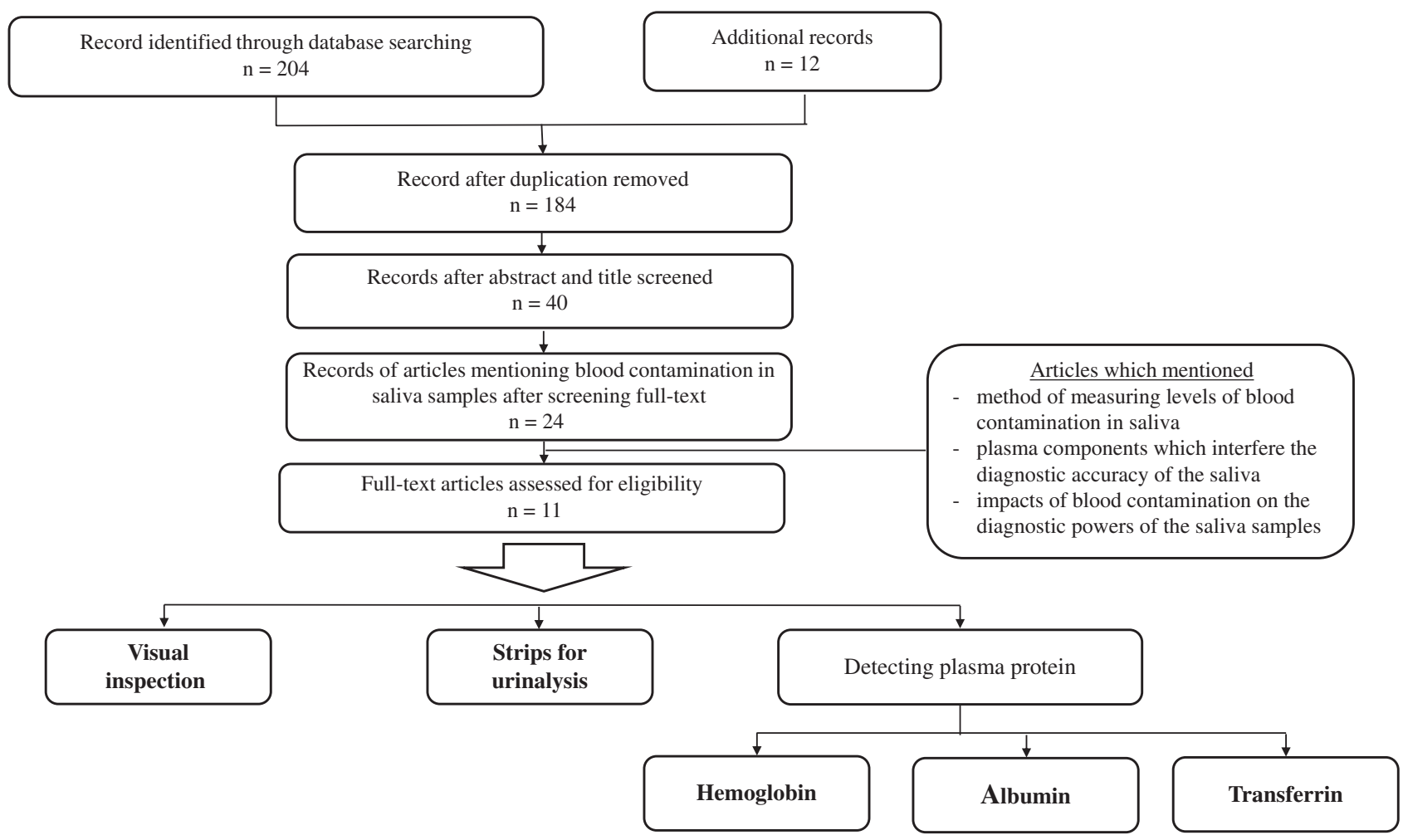

Figure 1: Flow chart of the literature review process using records based on the initial search.

to detect hemoglobin levels in whole saliva proved to be difficult [49]. To overcome this technical limitation, other methods, including the use of automated blood analyzer
[42, 45], spectrophotometry [47], mass spectrometry [50], and anti-human hemoglobin antibodies [43, 45, 46, 48] have been applied. Nonetheless, the accuracy of these

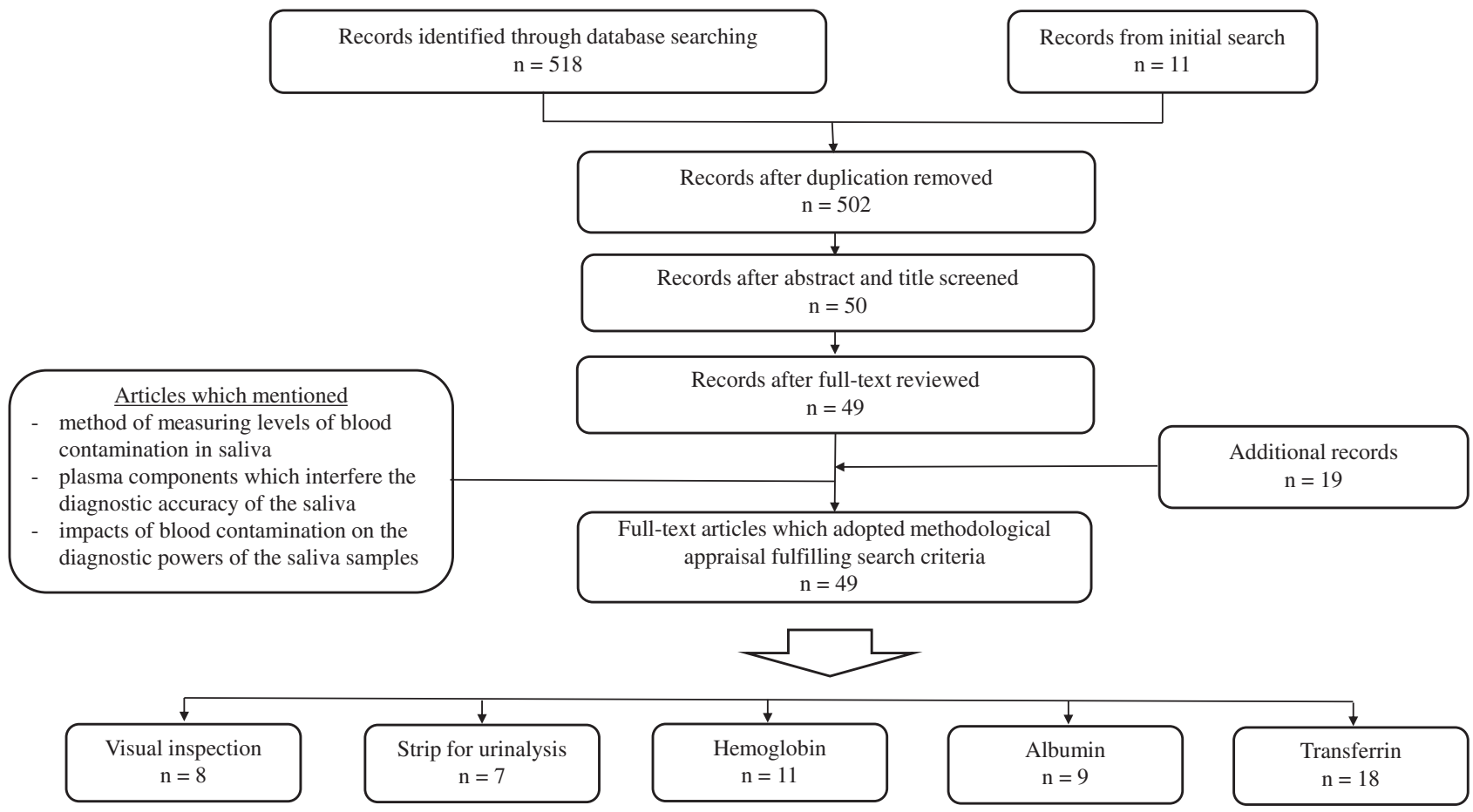

Figure 2: Flow chart of the literature review process using records based on a second search. 
methods is still questionable because one study has suggested the lack of correlations between periodontal health and salivary hemoglobin levels measured using hemoglobin antibodies [45]. Moreover, the measurement of free hemoglobin levels in centrifuged whole saliva samples by mass spectrometry did not yield reproducible results [50]. Forensic kits for bloodstains based on the principle of chromatographic immunoassay have not shown consistent results and potential false positive results in saliva samples [51]. In addition to these technical limitations, the level of hemoglobin can be influenced by other factors that one study has shown that increased hemoglobin levels in whole saliva were detected in obese patients [50]. Due to these reasons, hemoglobin has not been regarded as a commonly accepted marker of blood contamination in saliva, thus indicating the need for other advanced methods to measure the salivary levels of hemoglobin.

Interestingly, hemoglobin can interfere with the measurement of analytes in saliva. The interference of hemoglobin with salivary testosterone [52] and oxidative stress marker measurements has been suggested [30]. Therefore, it is important to consider the influences of both blood contamination and hemoglobin on the diagnostic accuracy of salivary samples when measuring the levels of these analytes in saliva.

\section{Measuring the salivary levels of albumin}

Albumin is one of the major plasma proteins, but it has not been regarded as a normal component of glandular saliva. Thus, the presence of albumin in whole saliva is thought to be the result of contamination by exudates resulting from gingival inflammation or the destruction of the oral mucosa. In fact, albumin levels in whole saliva increased concomitantly with an increase in the gingival index, representing the degree of gingival inflammation in the oral cavity $[53,54]$ and were elevated in patients with HIV infection or stomatitis with decreased mucosal integrity $[55,56]$. Therefore, the albumin level in whole saliva has been regarded as a quantitative indicator of blood traces in saliva. However, elevated albumin levels in whole saliva were also detected in hospitalized frail elderly subjects [57] and patients with certain conditions such as oral leukoplakia, oral squamous cell carcinoma, and obesity [50,58]. These conditions might be related to the destruction of the oral mucosal integrity or increased gingival inflammation. Nevertheless, further research is needed to determine the validity of albumin as a reliable marker of blood contamination in saliva.
Albumin can interfere with salivary analyte measurements, particularly in proteomic analysis, because the presence of high-abundance proteins such as albumin could either mask or reduce the separation sensitivity for detecting low-abundance proteins in various disease conditions [59-61].

\section{Measuring the salivary levels of transferrin}

Measuring the salivary levels of transferrin [28] has been regarded as one of the most widely adopted methods for determining the levels of blood contamination in saliva. In a previously conducted human study, transferrin was not detected in glandular saliva, but was identified in whole saliva using two-dimensional gel electrophoresis, leading the authors to suggest that transferrin in whole saliva would not originate from the salivary glands but from the local environment in an individual's oral cavity [62]. However, this study used only four participants, presented the data of one female, and discussed the possibility of inter-individual differences. Several studies have also reported that the measurement of the salivary levels of transferrin showed better results in comparison to the detection of blood using the naked eye or strips for urinalysis, and transferrin has been regarded as the most valid surrogate marker for the quantification of blood contamination in saliva $[26,28,63,64]$. The salivary levels of transferrin of $\geq 5 \mathrm{mg} / \mathrm{L}$ for the measurement of testosterone and $>10 \mathrm{mg} / \mathrm{L}$ for cortisol and dehydroepiandrosterone have been suggested as thresholds to determine the accuracy of salivary immunoassay results [28]. A commercial kit for detecting the salivary levels of transferrin has been used to determine the levels of blood contamination in saliva samples [27, 65-69]. However, recent research findings have suggested that this method may also have problems in applying for clinical and research purposes using whole saliva. Therefore, in the present study, we introduced several factors, which could influence the salivary levels of transferrin, except gingival inflammation and deteriorations of the oral mucosal integrity.

\section{Synthesis by salivary glands and tumor cells}

The main hypothesis for using transferrin as an appropriate marker for blood contamination in saliva samples is that transferrin does not originate from the salivary glands. However, an endogenous transferrin synthesis mechanism in rat parotid acinar cells and active transportation to parotid acinar cells after its synthesis in hepatic 
cells have been suggested in an animal study, thus implying the presence of other possible sources of transferrin in saliva [70].

In a human study, the transferrin level was found to be significantly increased in the whole saliva of patients with head and neck squamous cell carcinomas compared with that of unaffected controls [71]. Moreover, the salivary levels of transferrin showed positive correlations with tumor size [72]. Transferrin is an essential element in cell growth, because it is usually involved in iron-dependent metabolic processes such as DNA synthesis, electron transport, mitogenic signaling pathways, and cell proliferation and survival [73]. Thus, the expression amount of transferrin can be increased in rapidly growing tissues. As a result, the adequacy of transferrin as a blood contamination marker in whole saliva is questionable because transferrin can be synthesized in the salivary glands and its concentration can be influenced by specific conditions and pathologies.

\section{Age and menstruation cycle}

An age-related decrease in the salivary levels of transferrin levels has been reported [74] and in our previous study, we showed higher salivary levels of transferrin in young females despite the presence of a lower gingival index, in comparison to the older females [75]. This may be attributed to the levels of gonadal hormones and the process of menopause, which may affect the synthesis of transferrin, an iron-containing protein. The proliferative phase, including the follicular and ovulatory phases, is accompanied by an increased demand for transferrin due to active metabolism of proliferating endometrial cells. Consequently, the level of transferrin in blood during the proliferative phase needs to be elevated [73]. Likewise, the salivary levels of transferrin appeared to be higher during the ovulatory phase than those during other phases [68] and the transferrin levels in blood were lower in post-menopausal women than in pre-menopausal women [76]. Therefore, age and gonadal hormones may influence the salivary levels of transferrin.

\section{Salivary flow rate and chewing ability}

A previous study had suggested the influence of salivary flow rate on the secretion and concentration of transferrin in saliva [75]. This study suggested that effects of salivary flow on the level of transferrin in saliva and existence of dilution effects in the stimulated condition. In another study, the influences of both salivary and gingival crevicular flow rates on the final concentrations of plasma proteins in the oral cavity (up to ninefold differences in the salivary levels of transferrin) were shown [77].

The chewing performance may also affect the salivary levels of transferrin [75]. Tooth mobility induced by chewing transmits a stimulus to the walls of the gingival blood vessel, which can lead to an increase in blood vessel transudation [78]. A higher number of teeth and increased biting force may lead to elevated amounts of exudates in the gingival crevice, which may eventually increase the level of blood contamination in saliva.

\section{Oral microorganisms}

The role of transferrin in saliva has not been fully investigated. However, transferrin may have bacteriostatic effects because lactoferrin, an analog of transferrin, exhibits antimicrobial properties. A previous study focusing on the iron-binding capacities of lactoferrin and transferrin has suggested mechanisms by which the iron-binding proteins can damage the outer membranes of Gram-negative microorganisms by altering membrane permeability or creating an iron-deficient environment that could limit bacterial growth [79]. Other studies have shown that the concentrations of lactoferrin and transferrin were significantly decreased in patients with oral candidiasis and suggested that this might influence the occurrence of oral candidiasis [80, 81]. Although the biological role of transferrin in saliva is not fully understood at present, oral microorganisms might affect the salivary levels of transferrin.

\section{Saliva collection tubes and blood contamination}

To improve the clinical usability of saliva samples, it is essential to standardize the procedures of collection, processing, and storage of saliva samples. Several saliva collecting methods and devices have been developed to overcome this limitation.

Three types of collection tubes for saliva samples have been proposed. The first type is in the form of a simple tube which facilitates saliva collection by the passive drooling and spitting procedure or provides a 
volume adequacy indicator. Secondly, cotton roll and other absorbing materials including inert polymers have been used as media in the devices for collecting saliva, leading to the well-known Salivette ${ }^{\circledR}$ and Intercept ${ }^{\circledR}$. The absorbing materials are soaked into saliva and then the soaked materials are inserted into a container. The container is centrifuged to obtain the saliva. However, several studies have demonstrated the low recovery of several substances including steroid hormones and peptides when using this method [82-84]. Considering that many proposed methods for measuring the level of blood contamination in saliva samples mainly adopted the method of measuring plasma protein levels in saliva, saliva collection using these tubes may also affect the blood contamination levels in samples. Furthermore, some methods adopted the procedures of chewing the absorbent materials which may lead to increase the gingival exudates. The increased gingival exudates could cause increasing the likelihood of blood contamination in the collected samples. Several reports have mentioned the increased concentrations of oxidative stress markers and C-reactive protein in saliva samples collected by the chewing procedure using Salivette ${ }^{\circledR}$ with cotton medium compared to those collected by swab or drooling method [85, 86]. The third type of collector such as SalivaBio Oral Swab ${ }^{\circledR}$ and ORAcollect $\cdot \mathrm{DNA}^{\circledR}$ adopted a swab method that captures cells and saliva in the mouth. These applicators are rubbed on the oral mucosal surfaces and enable to secure a small quantity of saliva and cells.

Though saliva is a promising biological sample for diagnostic purposes, types of collection tubes may affect the accuracy of the analytic results and also the level of blood contamination in saliva samples. Therefore, it is necessary to select collection tubes that do not interfere with the accuracy of the analytic results, while allowing standardization of the sampling process.

\section{Recommendation for clinical laboratory}

Contemporary salivary research and diagnostics focus on the measurement of salivary constituents. The components in whole saliva could be classified into three groups, constituents which are originated from plasma and are not secreted from the glandular salivary glands (ex. albumin), those mainly produced from the salivary glands (ex. histatins), and those from both sources (ex. steroid hormones, cytokines, oxidative stress markers, and electrolytes) [19, 87]. Several components in the third group are transported into saliva from plasma through passive diffusion, active transport, or ultrafiltration process [19, 87]. Otherwise, some of them are locally produced in the salivary glands, and others are transported from plasma to saliva directly through gingival exudates [19, 87]. Generally, the concentrations of salivary components in the first and third groups could be influenced by the level of blood contamination in saliva samples. Especially, most components in the third group show much higher concentrations in plasma than in saliva and the concentrations of these analytes in saliva appear to be inevitably elevated when blood leakage reaches a certain level. Therefore, consideration of the usefulness of saliva samples in terms of the level of blood contamination has been suggested. It has been reported that the salivary levels of transferrin of $\geq 5 \mathrm{mg} / \mathrm{L}$ for the measurement of testosterone and $>10 \mathrm{mg} / \mathrm{L}$ for cortisol and dehydroepiandrosterone have been suggested as thresholds to determine the accuracy of analytic results [28]. Therefore, routine check-up of degree of blood contamination in every salivary sample would be recommended, especially in the analyses of salivary components of which origin is plasma or those of which concentrations are much higher in plasma compared to in saliva (Table 2).

Table 2: Recommendation of screening blood contamination in saliva samples.

\begin{tabular}{|c|c|c|c|c|}
\hline \multirow{2}{*}{$\begin{array}{l}\text { Origin of component } \\
\text { Plasma }\end{array}$} & \multirow{2}{*}{$\begin{array}{l}\begin{array}{l}\text { Transport mechanism from } \\
\text { plasma to whole saliva }\end{array} \\
\text { Gingival inflammatory } \\
\text { exudates and damaged } \\
\text { oral mucosa }\end{array}$} & \multirow{2}{*}{$\begin{array}{l}\text { Example of component } \\
\text { Albumin }\end{array}$} & \multicolumn{2}{|c|}{ Screening for blood contamination } \\
\hline & & & Necessary & \\
\hline Glandular saliva & & Histatins & Not necessary & \\
\hline \multirow[t]{3}{*}{$\begin{array}{l}\text { Plasma and glandular } \\
\text { saliva }\end{array}$} & Passive diffusion & $\begin{array}{l}\text { Cortisol, testosterone, } \\
\text { dehydroepiandrosterone }\end{array}$ & Recommend & $\begin{array}{l}\text { Depends on the difference } \\
\text { of concentration between } \\
\text { plasma and saliva }\end{array}$ \\
\hline & Active transport & Immunoglobulin A & Recommend & \\
\hline & Ultrafiltration & $\begin{array}{l}\text { Dehydroepiandrosterone } \\
\text { sulfate }\end{array}$ & Recommend & \\
\hline
\end{tabular}




\section{Conclusions}

Previous studies on the behavioral and diagnostic aspects of saliva have usually adopted quantitative analyses of whole saliva samples. The diagnostic value of saliva is affected by the level of blood contamination originating from either gingival inflammation or loss of oral mucosal integrity. Several methods including visual inspection, use of strips for urinalysis, and measurement of plasma proteins levels in saliva, have been used to detect the level of blood contamination in saliva but these methods have several limitations. Although transferrin has been regarded as one of the most reliable markers in saliva, several factors, including age, gonadal hormones, salivary flow rate, chewing performance, oral microorganisms, and pathologies, might affect the salivary levels of transferrin. Further studies for the identification of additional suitable markers of blood contamination in saliva samples are warranted.

Author contributions: Jeong-Hyun Kang designed the study, collected the literature, and drafted the paper. Hong-Seop Kho designed the study, supervised all procedures, and wrote the manuscript. Both authors revised the manuscript and approved the final version. All the authors have accepted responsibility for the entire content of this submitted manuscript and approved submission.

Research funding: This research was supported by the National Research Foundation of Korea (NRF) grant funded by the Korea government (MSIP) (No. 2016R1A2B4007286). Employment or leadership: None declared. Honorarium: None declared.

Competing interests: The funding organization(s) played no role in the study design; in the collection, analysis, and interpretation of data; in the writing of the report; or in the decision to submit the report for publication.

\section{References}

1. Malamud D. Saliva as a diagnostic fluid. Dent Clin North Am 2011;55:159-78.

2. Corstjens PL, Abrams WR, Malamud D. Saliva and viral infections. Periodontol 2000 2016;70: 93-110.

3. Chiappin S, Antonelli G, Gatti R, De Palo EF. Saliva specimen: a new laboratory tool for diagnostic and basic investigation. Clin Chim Acta 2007;383:30-40.

4. Saxena S, Kumar S. Saliva in forensic odontology: a comprehensive update. J Oral Maxillofac Pathol 2015;19:263-5.

5. Wood P. Salivary steroid assays - research or routine? Ann Clin Biochem 2009;46:183-96.
6. Aqrawi LA, Galtung HK, Vestad B, Ovstebo R, Thiede B, Rusthen $\mathrm{S}$, et al. Identification of potential saliva and tear biomarkers in primary Sjogren's syndrome, utilising the extraction of extracellular vesicles and proteomics analysis. Arthritis Res Ther 2017;19:14.

7. Arshad MK, Bin Mohamad Fathil MF, Gopinath SC, Ruslinda AR, Md Nor MN, Lam HY, et al. Cardiac biomarkers: invasive to noninvasive assessments. Curr Med Chem 2016;23:4270-84.

8. Goncalves AC, Marson FA, Mendonca RM, Ribeiro JD, Ribeiro AF, Paschoal IA, et al. Saliva as a potential tool for cystic fibrosis diagnosis. Diagn Pathol 2013;8:46.

9. Masters JM, Noyce AJ, Warner TT, Giovannoni G, Proctor GB. Elevated salivary protein in Parkinson's disease and salivary DJ-1 as a potential marker of disease severity. Parkinsonism Relat Disord 2015;21:1251-5.

10. Shi M, Sui YT, Peskind ER, Li G, Hwang H, Devic I, et al. Salivary tau species are potential biomarkers of Alzheimer's disease. J Alzheimers Dis 2011;27:299-305.

11. Xiao H, Langerman A, Zhang Y, Khalid O, Hu S, Cao CX, et al. Quantitative proteomic analysis of microdissected oral epithelium for cancer biomarker discovery. Oral Oncol 2015;51:1011-9.

12. Du Y, Zhang W, Wang ML. An on-chip disposable salivary glucose sensor for diabetes control. J Diabetes Sci Technol 2016;10:1344-52.

13. Peng CH, Xia YC, Wu Y, Zhou ZF, Cheng P, Xiao P. Influencing factors for saliva urea and its application in chronic kidney disease. Clin Biochem 2013;46:275-7.

14. Porto-Mascarenhas EC, Assad DX, Chardin H, Gozal D, De Luca Canto G, Acevedo AC, et al. Salivary biomarkers in the diagnosis of breast cancer: a review. Crit Rev Oncol Hematol 2017;110:62-73.

15. Zhang L, Farrell JJ, Zhou H, Elashoff D, Akin D, Park NH, et al. Salivary transcriptomic biomarkers for detection of resectable pancreatic cancer. Gastroenterology 2010;138:949-57.

16. Zilberman Y, Sonkusale SR. Microfluidic optoelectronic sensor for salivary diagnostics of stomach cancer. Biosens Bioelectron 2015;67:465-71.

17. Fransen K, Vermoesen T, Beelaert G, Menten J, Hutse V, Wouters $\mathrm{K}$, et al. Using conventional HIV tests on oral fluid. J Virol Methods 2013;194:46-51.

18. Jasim H, Carlsson A, Hedenberg-Magnusson B, Ghafouri B, Ernberg $M$. Saliva as a medium to detect and measure biomarkers related to pain. Sci Rep 2018;8:3220.

19. Nunes LA, Mussavira S, Bindhu OS. Clinical and diagnostic utility of saliva as a non-invasive diagnostic fluid: a systematic review. Biochem Med (Zagreb) 2015;25:177-92.

20. Brutis CA, Bruns DE. Tietz fundamentals of clinical chemistry and molecular diagnostics. St. Louis, MO: Elsevier Saunders, 2014.

21. Nunes LA, Brenzikofer R, Macedo DV. Reference intervals for saliva analytes collected by a standardized method in a physically active population. Clin Biochem 2011;44:1440-4.

22. Patidar KA, Parwani RN, Wanjari SP. Correlation of salivary and serum IgG, IgA levels with total protein in oral submucous fibrosis. J Oral Sci 2011;53:97-102.

23. Gallagher P, Leitch MM, Massey AE, McAllister-Williams RH, Young AH. Assessing cortisol and dehydroepiandrosterone (DHEA) in saliva: effects of collection method. J Psychopharmacol 2006;20:643-9.

24. Patel RS, Shaw SR, Macintyre H, McGarry GW, Wallace AM. Production of gender-specific morning salivary cortisol reference intervals using internationally accepted procedures. Clin Chem Lab Med 2004;42:1424-9. 
25. Shirtcliff EA, Granger DA, Schwartz E, Curran MJ. Use of salivary biomarkers in biobehavioral research: cotton-based sample collection methods can interfere with salivary immunoassay results. Psychoneuroendocrinology 2001; 26:165-73.

26. Kivlighan KT, Granger DA, Schwartz EB, Nelson V, Curran M, Shirtcliff EA. Quantifying blood leakage into the oral mucosa and its effects on the measurement of cortisol, dehydroepiandrosterone, and testosterone in saliva. Horm Behav 2004; 46:39-46.

27. Behr GA, Patel JP, Coote M, Moreira JC, Gelain DP, Steiner M, et al. A statistical method to calculate blood contamination in the measurement of salivary hormones in healthy women. Clin Biochem 2017;50:436-9.

28. Schwartz EB, Granger DA. Transferrin enzyme immunoassay for quantitative monitoring of blood contamination in saliva. Clin Chem 2004;50:654-6.

29. Rehak NN, Cecco SA, Csako G. Biochemical composition and electrolyte balance of "unstimulated" whole human saliva. Clin Chem Lab Med 2000;38:335-43.

30. Kamodyova N, Banasova L, Jansakova K, Koborova I, Tothova L, Stanko P, et al. Blood contamination in saliva: impact on the measurement of salivary oxidative stress markers. Dis Markers 2015;2015:479251.

31. Hoferl M, Krist S, Buchbauer G. Adaptation of DELFIA cortisol kit for determination of salivary cortisol concentration. Arch Pharm (Weinheim) 2005;338:493-7.

32. Kanegane K, Penha SS, Munhoz CD, Rocha RG. Dental anxiety and salivary cortisol levels before urgent dental care. J Oral Sci 2009;51:515-20.

33. Miles MV, Tang PH, Glauser TA, Ryan MA, Grim SA, Strawsburg $\mathrm{RH}$, et al. Topiramate concentration in saliva: an alternative to serum monitoring. Pediatr Neurol 2003;29:143-7.

34. Goncharov N, Katsya G, Dobracheva A, Nizhnik A, Kolesnikova G, Herbst $V$, et al. Diagnostic significance of free salivary testosterone measurement using a direct luminescence immunoassay in healthy men and in patients with disorders of androgenic status. Aging Male 2006;9:111-2.

35. Granger DA, Shirtcliff EA, Booth A, Kivlighan KT, Schwartz EB. The "trouble" with salivary testosterone. Psychoneuroendocrinology 2004;29:1229-40.

36. Bernabe DG, Tamae AC, Miyahara GI, Sundefeld ML, Oliveira SP, Biasoli ER. Increased plasma and salivary cortisol levels in patients with oral cancer and their association with clinical stage. J Clin Pathol 2012;65:934-9.

37. Mazur AS, Edelbrock S. Sex differences in testosterone response to a video game contest. Evol Hum Behav 1997;18:317-26.

38. Piazza M, Chirianni A, Picciotto L, Cataldo PT, Borgia G, Orlando R. Blood in saliva of patients with acquired immunodeficiency syndrome: possible implication in sexual transmission of the disease. J Med Virol 1994;42:38-41.

39. Poon H, Elliott J, Modler J, Fregeau C. The use of Hemastix and the subsequent lack of DNA recovery using the Promega DNA IQ system. J Forensic Sci 2009;54:1278-86.

40. Selby C, Lobb PA, Jeffcoate WJ. Sex hormone binding globulin in saliva. Clin Endocrinol (Oxf) 1988;28:19-24.

41. Gertz M. Saliva on Hemastix produces false-positive results for blood. N Engl J Med 1983;308:1602.

42. Celecova V, Kamodyova N, Tothova L, Kudela M, Celec P. Salivary markers of oxidative stress are related to age and oral health in adult non-smokers. J Oral Pathol Med 2013;42:263-6.
43. Choi JS, Kim HE, Donnelly LR. Relationship between salivary haemoglobin and number of remaining teeth in older Koreans. Gerodontology 2018;35:25-32.

44. Lin H, Maeda K, Fukuhara A, Shimomura I, Ito T. Molecular expression of adiponectin in human saliva. Biochem Biophys Res Commun 2014;445:294-8.

45. Nam SH, Jung HI, Kang SM, Inaba D, Kwon HK, Kim BI. Validity of screening methods for periodontitis using salivary hemoglobin level and self-report questionnaires in people with disabilities. J Periodontol 2015;86:536-45.

46. Okada A, Nomura Y, Sogabe K, Oku H, Sato Gillbreath A, Hino $F$, et al. Comparison of salivary hemoglobin measurements for periodontitis screening. J Oral Sci 2017;59:63-9.

47. Ross RS, Viazov S, Runde V, Schaefer UW, Roggendorf M. Detection of TT virus DNA in specimens other than blood. J Clin Virol 1999;13:181-4.

48. Shimazaki Y, Akifusa S, Takeshita T, Shibata Y, Doi Y, Hata J, et al. Effectiveness of the salivary occult blood test as a screening method for periodontal status. J Periodontol 2011;82:581-7.

49. Kawai KS, Kaneda T, Oka T, Sato K, Katumata Y. A high sensitive method for determination of hemoglobin applicable to quantitative analysis in oral bleeding. Japanese J Oral Max Surg 1985;31:1854-8.

50. Range H, Leger T, Huchon C, Ciangura C, Diallo D, Poitou C, et al. Salivary proteome modifications associated with periodontitis in obese patients. J Clin Periodontol 2012;39:799-806.

51. Horjan I, Barbaric L, Mrsic G. Applicability of three commercially available kits for forensic identification of blood stains. J Forensic Leg Med 2016;38:101-5.

52. Durdiakova J, Fabryova H, Koborova I, Ostatnikova D, Celec P. The effects of saliva collection, handling and storage on salivary testosterone measurement. Steroids 2013;78:1325-31.

53. Henskens YM, van der Velden U, Veerman EC, Nieuw Amerongen AV. Protein, albumin and cystatin concentrations in saliva of healthy subjects and of patients with gingivitis or periodontitis. J Periodontal Res 1993;28:43-8.

54. Oppenheim GG. Historical perspectives and present. In: Wong DT, editor. Salivary diagnostics. Ames, IA: Wiley-Blackwell, 2008:79-93.

55. Izutsu KT, Truelove EL, Bleyer WA, Anderson WM, Schubert MM, Rice JC. Whole saliva albumin as an indicator of stomatitis in cancer therapy patients. Cancer 1981;48:1450-4.

56. Mellanen L, Sorsa T, Lahdevirta J, Helenius M, Kari K, Meurman $J$ H. Salivary albumin, total protein, $\lg A, \lg G$ and IgM concentrations and occurrence of some periodontopathogens in HIVinfected patients: a 2-year follow-up study. J Oral Pathol Med 2001;30:553-9.

57. Meurman JH, Rantonen P, Pajukoski H, Sulkava R. Salivary albumin and other constituents and their relation to oral and general health in the elderly. Oral Surg Oral Med Oral Pathol Oral Radiol Endod 2002;94:432-8.

58. Metgud R, Patel S. Serum and salivary levels of albumin as diagnostic tools for oral pre-malignancy and oral malignancy. Biotech Histochem 2014;89:8-13.

59. Kaczor-Urbanowicz KE, Martin Carreras-Presas C, Aro K, Tu M, Garcia-Godoy F, Wong DT. Saliva diagnostics - Current views and directions. Exp Biol Med (Maywood) 2017;242:459-72.

60. Krief G, Deutsch O, Gariba S, Zaks B, Aframian DJ, Palmon A. Improved visualization of low abundance oral fluid proteins after triple depletion of alpha amylase, albumin and IgG. Oral Dis 2011;17:45-52. 
61. Krief G, Deutsch O, Zaks B, Wong DT, Aframian DJ, Palmon A. Comparison of diverse affinity based high-abundance protein depletion strategies for improved bio-marker discovery in oral fluids. J Proteomics 2012;75:4165-75.

62. Walz A, Stuhler K, Wattenberg A, Hawranke E, Meyer HE, Schmalz G, et al. Proteome analysis of glandular parotid and submandibular-sublingual saliva in comparison to whole human saliva by two-dimensional gel electrophoresis. Proteomics 2006;6:1631-9.

63. Granger DA, Cicchetti D, Rogosch FA, Hibel LC, Teisl M, Flores E. Blood contamination in children's saliva: prevalence, stability, and impact on the measurement of salivary cortisol, testosterone, and dehydroepiandrosterone. Psychoneuroendocrinology 2007;32:724-33.

64. Kivlighan KT, Granger DA, Schwartz EB. Blood contamination and the measurement of salivary progesterone and estradiol. Horm Behav 2005;47:367-70.

65. Kang JH, Kim YY, Chang JY, Kho HS. Relationships between oral MUC1 expression and salivary hormones in burning mouth syndrome. Arch Oral Biol 2017;78:58-64.

66. Kho HS, Chang JY, Kim YY, Kim Y. MUC1 and Toll-like receptor-2 expression in burning mouth syndrome and oral lichen planus. Arch Oral Biol 2013;58:837-42.

67. Kim HI, Kim YY, Chang JY, Ko JY, Kho HS. Salivary cortisol, 17beta-estradiol, progesterone, dehydroepiandrosterone, and alpha-amylase in patients with burning mouth syndrome. Oral Dis 2012;18:613-20.

68. Lee YH, Kim YY, Chang JY, Kho HS. Changes in oral mucosal MUC1 expression and salivary hormones throughout the menstrual cycle. Oral Dis 2015;21:962-8.

69. Suh KI, Kim YK, Kho HS. Salivary levels of IL-1beta, IL-6, IL-8, and TNF-alpha in patients with burning mouth syndrome. Arch Oral Biol 2009;54:797-802.

70. Nashida T, Yoshie S, Imai A, Shimomura H. Transferrin secretory pathways in rat parotid acinar cells. Arch Biochem Biophys 2009;487:131-8.

71. Dowling P, Wormald R, Meleady P, Henry M, Curran A, Clynes $M$. Analysis of the saliva proteome from patients with head and neck squamous cell carcinoma reveals differences in abundance levels of proteins associated with tumour progression and metastasis. J Proteomics 2008;71:168-75.

72. Jou YJ, Lin CD, Lai CH, Chen CH, Kao JY, Chen SY, et al. Proteomic identification of salivary transferrin as a biomarker for early detection of oral cancer. Anal Chim Acta 2010; 681:41-8.
73. Parmar T, Gadkar-Sable S, Savardekar L, Katkam R, Dharma S, Meherji $\mathrm{P}$, et al. Protein profiling of human endometrial tissues in the midsecretory and proliferative phases of the menstrual cycle. Fertil Steril 2009;92:1091-103.

74. Tanida T, Ueta E, Tobiume A, Hamada T, Rao F, Osaki T. Influence of aging on candidal growth and adhesion regulatory agents in saliva. J Oral Pathol Med 2001;30:328-35.

75. Kang JH, Lee YH, Kho HS. Clinical factors affecting salivary transferrin level, a marker of blood contamination in salivary analysis. BMC Oral Health 2018;18:49.

76. Kim C, Nan B, Kong S, Harlow S. Changes in iron measures over menopause and associations with insulin resistance. J Womens Health (Larchmt) 2012;21:872-7.

77. Helmerhorst EJ, Dawes C, Oppenheim FG. The complexity of oral physiology and its impact on salivary diagnostics. Oral Dis 2018;24:363-71.

78. Lagos ML, Sant'ana AC, Greghi SL, Passanezi E. Keratinized gingiva determines a homeostatic behavior of gingival sulcus through transudation of gingival crevice fluid. Int J Dent 2011;2011:953135.

79. Ellison RT, 3rd, Giehl TJ, LaForce FM. Damage of the outer membrane of enteric gram-negative bacteria by lactoferrin and transferrin. Infect Immun 1988;56:2774-81.

80. Ueta E, Tanida T, Doi S, Osaki T. Regulation of Candida albicans growth and adhesion by saliva. J Lab Clin Med 2000;136:66-73.

81. Tanida T, Okamoto T, Okamoto A, Wang H, Hamada T, Ueta $E$, et al. Decreased excretion of antimicrobial proteins and peptides in saliva of patients with oral candidiasis. J Oral Pathol Med 2003;32:586-94.

82. Groschl M, Kohler H, Topf HG, Rupprecht T, Rauh M. Evaluation of saliva collection devices for the analysis of steroids, peptides and therapeutic drugs. J Pharm Biomed Anal 2008;47:478-86.

83. Groschl M, Rauh M. Influence of commercial collection devices for saliva on the reliability of salivary steroids analysis. Steroids 2006;71:1097-100.

84. Toda M, Morimoto K. Comparison of saliva sampling methods for measurement of salivary adiponectin levels. Scand J Clin Lab Invest 2008;68:823-5.

85. Topkas E, Keith P, Dimeski G, Cooper-White J, Punyadeera C. Evaluation of saliva collection devices for the analysis of proteins. Clin Chim Acta 2012;413:1066-70.

86. Kamodyova N, Celec P. Salivary markers of oxidative stress and Salivette collection systems. Clin Chem Lab Med 2011;49:1887-90.

87. Bosch JA. The use of saliva markers in psychobiology: mechanisms and methods. Monogr Oral Sci 2014;24:99-108. 